\title{
SISTEM INFORMASI DARURAT PADA MINI MARKET MENGGUNAKAN MIKROKONTROLER ESP8266 BERBASIS INTERNET OF THINGS
}

\author{
Anugerah Deris ${ }^{\#)}$ \\ \#Program Studi IImu Komputer, FMIPA, Universitas Pakuan, Bogor, Indonesia \\ \#) Corresponding Author: anugrahderis@gmail.com
}

Article history: received 11 March 2019; revised 27 May 2019; accepted 21 June 2019

\begin{abstract}
Abstrak
Semakin meningkatnya tingkat kejahatan telah mendorong sistem intrumentasi dan teknologi untuk mengatasi dan mengungkap kasus kejahatan. Sistem informasi darurat di pasar mini menggunakan mikrokontroler ESP8266 dan telah dibangun dan dianalisis untuk mengatasi hal tersebut dengan basis Internet of Things. Sinyal yang dihasilkan dari alat ini pada pusat perbelanjaan memberikan informasi darurat di Situs Web pada unit keamanan. Hasil pengujian sistem menghasilkan delay 3.6 sekon untuk koneksi power suplay ke NodeMcu. sedangkan delay untuk menghitung Transmisi (sinyal respon) dari Unit Keamanan, dan delay untuk waktu alarm berbunyi adalah 0 sekon. Pada sistem ini, website bisa menerima informasi berupa titik kordinat dan alamat Minimarket
\end{abstract}

Kata kuncis: augmented reality (AR), markerless-based tracking, sistem respirasi.

\begin{abstract}
Increasing levels of crime have encouraged instrumentation and technology systems to deal with and expose crime cases. Emergency information systems on the mini market use ESP8266 microcontroller and have been built and analyzed to overcome this on the basis of the Internet of Things. Signals generated from this tool at shopping centers provide emergency information on the Website of the security unit. The results of the system test produced 3.6 seconds delay for power supply connections to NodeMcu. while the delay to calculate the Transmission (response signal) of the Security Unit, and the delay for the time the alarm sounds is 0 seconds. In this system, the website can receive information in the form of coordinate points and Minimarket addresses
\end{abstract}

Keywords: augmented reality (AR), markerless based tracking, respiratory system.

\section{Pendahuluan}

Era persaingan global yang ketat saat ini, populasi pertumbahan dan perkembangan perdagangan dunia usaha yang makin banyak dan cepat, kejahatan pun meningkat, oleh sebab itu pengawasan yang efektif dan efisien, harus dilakukan. Tingginya angka kejahatan di sebuah wlayah dan banyaknya jenis kejahatan spesifik yang terjadi di sebuah kelompok masyarakat merupakan sejumlah fenomena yang berkembang di sebuah masyarakat [1]. Sistem keamanan menggunakan kamera sebagai pemantau atau yang biasa disebut dengan CCTV akhir-akhir ini sering di gedung-gedung ataupun di mini market yang buka hingga 24 jam. Tujuannya adalah untuk memantau keadaan sekitar dari segala tindak kriminal sehingga memudahkan dalam pemantauan langsung serta sebagai alat bukti dalam proses peradilan [2]. Tetapi, itu saja tidak cukup dan membutuhkan waktu yang lama untuk menangkap pelaku yang melakukan tindak kriminal.

Penggunaan kamera dan CCTV untuk sistem keamanan telah banyak dilakukan oleh berbagai peneliti, diantaranya: Dwi Ely Kurniawan yang membuat rancaangan sistem kamera 
pengawas berbasis perangkat bergerak berbasis raspberry pi. [3]. Penelitian ini memiliki keterbatasan bahwa perlu adanya penggerak kamera agar area kamera terlihat lebih luas. Indri Handayani juga membuat optimalisasi sistem dan desain CCTV pada PT jet teknologi express berbasis cloud [4]. Kelemahan penelitian tersebut adalah tidak adanya autentifikasi diapplication yang digunakan di HP atau di PC.

Penelitian untuk sistem keamanan dapat dikembangkan menggunakan mikrokontroler ESP8266 berbasis Internet of Things melalui sinyal yang dihasil dari alat tersebut ini memberikan informasi darurat pada Website yang sudah dimiliki Unit keamanan. Suatu keamanan bagi pusat perbelanjaan yang buka hingga 24 jam yang sangat rawan akan terjadinya tindak kriminal dan bisa mengakibatkan korban jiwa. Pengawasan yang hanya mengandalkan CCTV saja tidak efektif, karena pelaku bisa melakukan tindak kriminal mengambil memori CCTV untuk menghilangkan barang bukti tindak kejahatan ataupun identitas pelaku. Internet of Things atau dikenal juga dengan singkatan loT, merupakan sebuah konsep yang bertujuan untuk memperluas manfaat dari konektivitas internet yang tersambung secara terus-menerus. Adapun kemampuan seperti berbagi data, remote control, dan sebagainya, termasuk juga pada benda di dunia nyata [5]. Contohnya bahan pangan, elektronik, koleksi, peralatan apa saja, termasuk benda hidup yang semuanya tersambung ke jaringan lokal dan global melalui sensor yang tertanam dan selalu aktif. Makna serupa yang lain, Internet of Things (IoT) adalah sebuah konsep suatu objek yang memiliki kemampuan untuk mentransfer data melalui jaringan [6]. Prinsip Alat ini yang dibuat adalah dapat memonitoring dan mengontrol peralatan elektronik rumah yang dapat dikendalikan dari jarak jauh menggunakan aplikasi android serta dapat mengetahui keadaan yang ada pada rumah. Alasan kenapa mengunakan aplikasi android dikarenakan pada zaman sekarang penggunaan smartphone sudah cukup banyak [7], oleh karena itu penelitian ini menggunakan aplikasi android sebagai media pengendali [8] Akses dapat dilakukan secara online menggunakan koneksi internet sehingga akan memudahkan penggunananya untuk melakukan monitoring dari jarak jauh. Aplikasi yang dibuat ini nantinya berguna untuk melihat keadaan ruangan atau tempat-tempat tertentu dan bisa dipantau langsung menggunakan perangkat Android. Jadi, situasi keadaan sekitar tetap bisa terpantau oleh aplikasi monitoring yang sudah terinstall pada smartphone Android tersebut asalkan terdapat koneksi internet yang memadai seperti Wi-fi atau layanan paket data operator seluler .

\section{Metode penelitian}

Metode yang digunakan dalam penelitian Model Informasi Darurat Pada Minimarket Berbasis Internet of Things (IoT) Dengan menggunakan metode penelitian bidang hardware programming yang ditunjukan pada gambar 1 .

Setelah tahap perencanaan selesai, dilanjutkan dengan tahap penelitian awal dari sistem yang akan dibuat, mulai dari pemilihan dan pengetesan komponen hingga pembuatan sketsa alur sistem. Pada tahap pengetesan komponen dilakukan pengetesan alat terhadap fungsi kerja komponen berdasarkan kebutuhan dari sistem yang akan dibuat. Tahap desain sistem mekanis merupakan tahap dilakukannya pertimbangan meliputi kebutuhan sistem yang akan dibuat terhadap desan mekanik, diantaranya: bentuk dan ukuran PCB (Printed Circuit Board), penempatan modul-modul elektronik, pengetesan sistem mekanik, dan bentuk desain ukuran interface system. Dalam tahap desain sistem elektrik terdapat beberapa hal yang harus diperhatikan, antara lain: Mikrokontroler ESP8266a, Baterai, LED, Buzzer, dan Button. Desain perangkat lunak yang digunakan dalam penelitian Informasi Darurat ini menggunakan perangkat lunak, Sublime Text, Fritzing, MS Office, dan Visio. Tahap tes fungsional dilakukan integrasi sistem elektrik dan software yang telah didesain. Tes ini dilakukan untuk meningkatkan performa dari perangkat lunak untuk me-manage sistem elektrik dan meminimalkan Bugs dari sistem yang akan dibuat. Setelah sistem elektrik diintegrasi dengan mikrokontroller, selanjutnya diintegrasi dalam struktur mekanik yang telah didesain. Lalu dilakukan tes fungsional keseluruhan sistem. Pada tahapan ini dilakukan pengetesan fungsi dari keseluruhan sistem. Apakah dapat berfungsi sesuai dengan konsep atau tidak. Bila ada sistem yang tidak dapat bekerja dengan baik maka harus dilakukan proses perakitan ulang pada setiap. Uji coba fungsional dilakukan untuk mengetahui apakah sistem yang dibuat dapat berjalan dengan baik. Pada tahap ini dilakukan pengujian yang bertujuan untuk mengetahui tegangan output komponen dengan menggunakan multimeter. Tahap uji coba validasi dilakukan dengan cara 
KOMPUTASI (Jurnal IImiah IImu Komputer dan Matematika)

Vol. 16, No. 2, Juli 2019, Hal. 283- 288

P-ISSN: 1693-7554, E-ISSN: 2654-3990

https://journal.unpak.ac.id/index.php/komputasi

menguji di khawatirkan terjadi kesalahan yang terdapat pada komponen-komponen yang diimplementasikan pada Informasi Darurat tersebut.

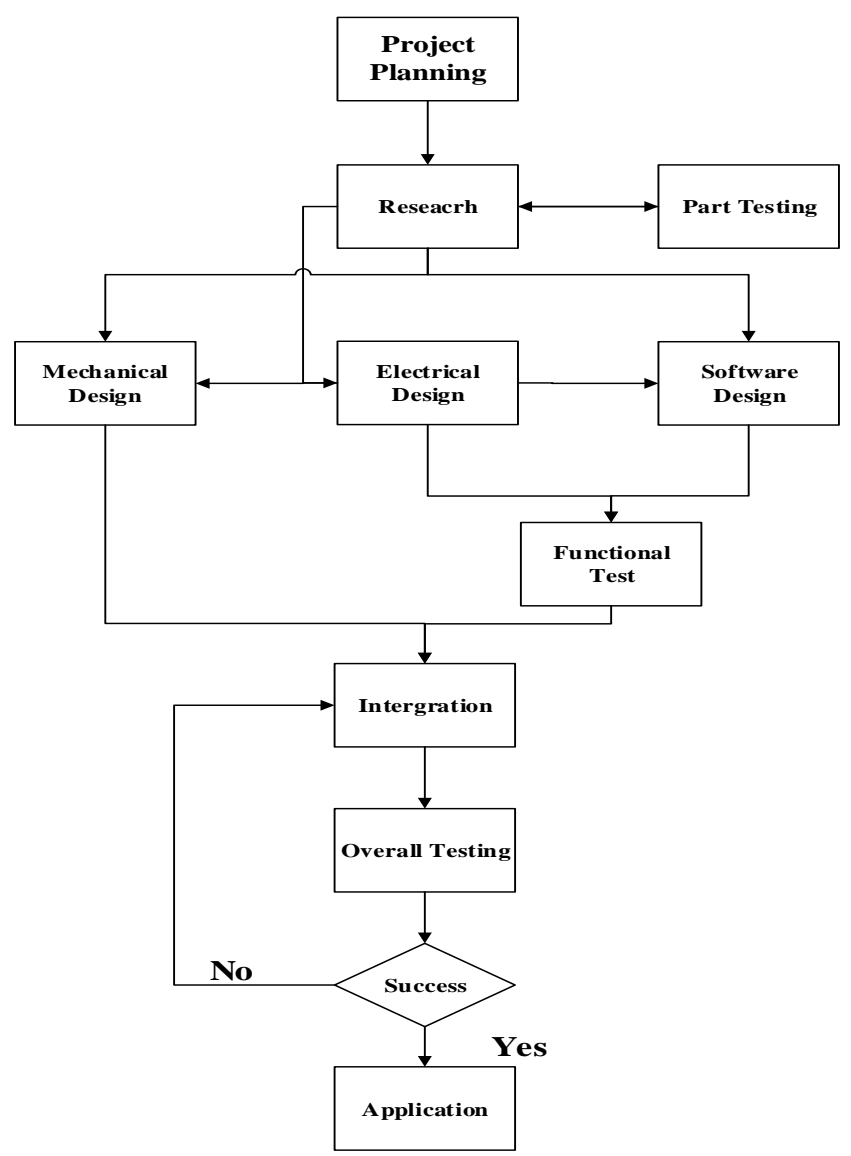

Gambar 1. Metode Penelitian HardwarePrograming.

\section{Analisis dan Hasil}

Proses perancangan hingga implementasi Informasi darurat pada Mini Market menggunakan mikrokontroler Esp8266 diimplementasikan dengan menggunakan modul-modul elektronik yang berukuran kecil sehingga dalam penempatan komponen elektronik tidak membutuhkan banyak tempat. Bagian utama sistem yang dirancang sebagaima gambar 2 .

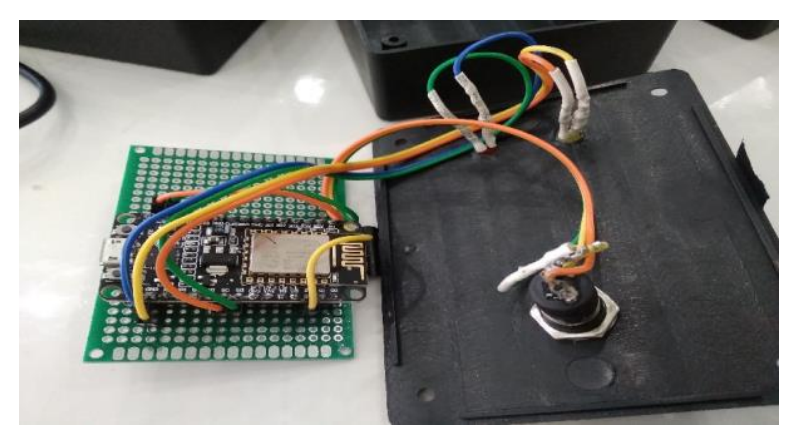

Gambar 2. Bagian utama informasi darurat

Pada tahap pembahasan akan dijelaskan mengenai bagaimana cara sistem bekerja, mulai dari tahap awal menerima arus $9 \mathrm{~V}$ hingga mengeksekusi perintah. Pada tahap awal sistem 
diberi daya oleh power suplay hingga menghidupkan NodeMcu ESP8266, Led, dan buzzer, kemudian akan memberikan informasi darurat jika di tekan. terdapat LED indicator ketika LED berwarna kuning maka kadan aman, jika LED indicator berwarna merah maka menandakan adanya situasi darurat disertai bunyi alarm (Buzzer). dan siap untuk mengirim informasi kondisi darurat ini pada website yang sudah dirancang sedemikian rupa agar Unit Keamanan siap dan sigap dalam kaadan darurat berupa pesan singkat yang berupa alamat lengkap, dan titik kordinat.

Pada model ini dipasang dua kondisi pada minimarket dan satu di Unit Keamanan sesuai zona terdekat. Yang dimana kondisi pertama ditekan adanya kondisi darurat, maka alat yangg berada di Unit Keamanan berbunyi dan memberikan notifikasi pada website. Jika kedua alat tersebut berbunyi dengan bersamaan maka akan ada dua kondisi siaga di website dan alat yang berada di Unit Keamanan akan memberikan dua respon sekaligus kepada minimarket yang sedang terjadi keadaan darurat. Hasil dari User Interface aplikasi dapat dilihat pada Tabel 2.

Tabel 1. Hasil user interface.

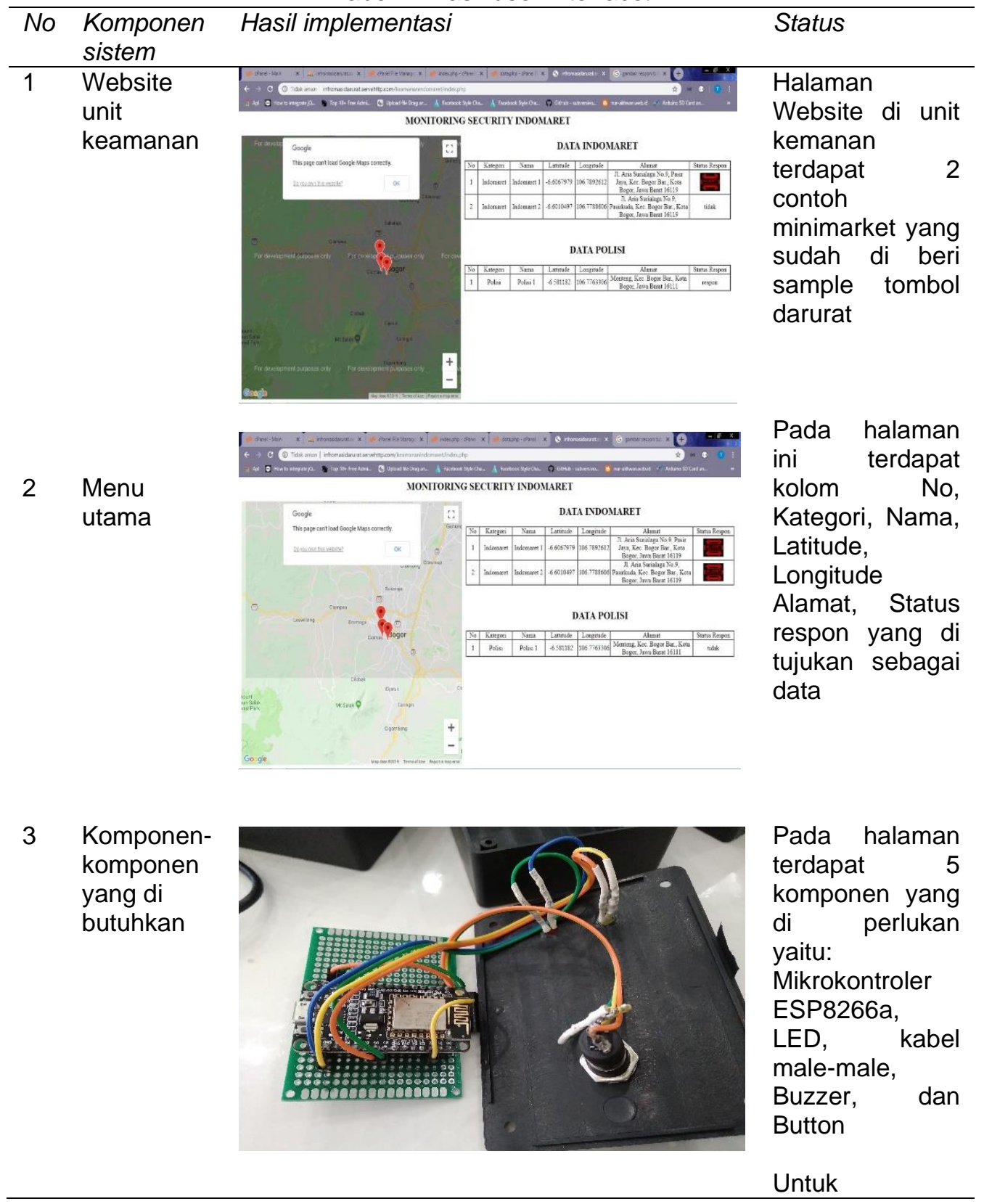


KOMPUTASI (Jurnal IImiah IImu Komputer dan Matematika)

Vol. 16, No. 2, Juli 2019, Hal. 283- 288

P-ISSN: 1693-7554, E-ISSN: 2654-3990

https://journal.unpak.ac.id/index.php/komputasi

$4 \quad$ Mulai

Pada tahap ini dilakukan uji coba (delay 1), (delay 2), dan (delay 3). Delay 1 untuk menghitung koneksi power suplay ke NodeMcu, delay 2 untuk menghitung Transmisi (sinyal respon) dari Unit Keamanan, dan delay 3 untuk menghitung lamanya alarm berbunyi. Pada Tabel 2 ditunjukkan bahwa dihasilkan delay yang berbeda untuk delay 1, delay 2, dan delay 3

Tabel 2. Uji coba satu alat

\begin{tabular}{|c|c|c|c|c|c|}
\hline Pengujian & Hasil uji & Website & $\begin{array}{l}\text { Delay } \\
1\end{array}$ & $\begin{array}{l}\text { Delay } \\
2\end{array}$ & $\begin{array}{l}\text { Delay } \\
3\end{array}$ \\
\hline Kondisi & akan & 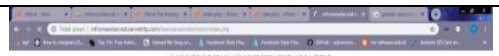 & $3.6 \mathrm{~s}$ & $150 \mathrm{~s}$ & $4.3 \mathrm{~s}$ \\
\hline $\begin{array}{l}\text { alat } 1 \text { Jıka } \\
\text { menekan } \\
\text { tombol }\end{array}$ & $\begin{array}{l}\text { langsung } \\
\text { terhubung } \\
\text { dengan } \\
\text { alat dan } \\
\text { website di } \\
\text { Unit } \\
\text { Keamanan }\end{array}$ & 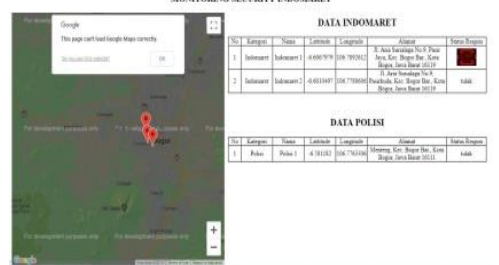 & & & \\
\hline
\end{tabular}

Uji coba ketiga menguji kondisi alat 1 dan alat 2 jika menekan tombol maka akan terhubung juga dengan alat dan website di Unit Keamanan akan tetapi dengan notifikasi 2(dua) dalam status kondisi darurat pada kolom website. dengan Delay 1 (3,6 detik) menghitung koneksi power suplay ke NodeMcu, delay 2 (2 menit 30 detik) menghitung Transmisi (sinyal respon) dari Unit Keamanan, dan Delay 3 (4,3 detik) menghitung lamanya alarm berbunyi. Tabel 3 .

Tabel 3. Uji coba dua alat

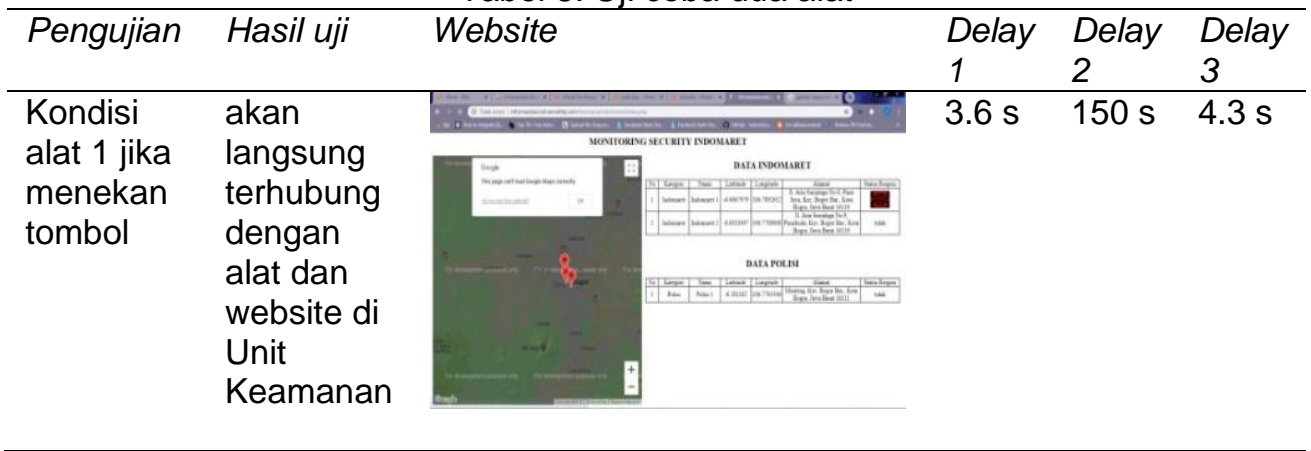

Hasil uji coba saat kondisi alat jika sudah direspon oleh Unit Keamanan dan sinyal led merah akan Berkedip menandakan Unit Keamanan sudah merespon dan bantuan akan segera datang. Dengan perolehan nilai delay 1 (3,6 detik) menghitung koneksi power suplay ke NodeMcu, delay 2 (3,4 detik) menghitung Transmisi (sinyal respon) sebagaimana pada Tabel 4. 
Tabel 4. Hasil perhitungan transmisi (sinyal respon)

\begin{tabular}{llllll}
\hline Pengujian & Hasil uji & Website & Delay & Delay & Delay \\
& & & 1 & 2 & 3 \\
\hline Kondisi & sinyal led & & $3.6 \mathrm{~s}$ & $3.4 \mathrm{~s}$ & $0 \mathrm{~s}$ \\
alat jika & merah & & & & \\
sudah di & akan & & & & \\
respon & Berkedip & & & & \\
oleh Unit & (respon) & & & & \\
Keamanan & Bantuan & & & & \\
& akan & & & & \\
& segera & & & & \\
& datang. & & & & \\
\end{tabular}

\section{Kesimpulan}

Sistem informasi darurat pada Minimarket telah dirancang dan diuji dengan baik untuk zona terdekat. SIstem ini mampu memberikan informasi darurat berupa sinyal dan akan di terima oleh website yang sudah dirancang dan diterima baik oleh Unit keamanan dengan nilai delay kurang dari $5 \mathrm{~s}$. Sistem ini dapat dikembangkan dengan penambahan sensor

\section{Referensi}

[1] R. Tutrianto. 2018. Munculnya kejahatan di Wilayah Perkotaan (Studi pada Kota Pekanbaru). Jurnal Kriminologi Indonesia, 14(1): 15-24.

[2] R. A. Arianda. 2017. Penggunaan Alat Bukti Rekaman CCTV (Closed Circuit Television) dalam Proses Peradilan Pidana. Poenale: Jurnal Bagian Hukum Pidana, 5(3).

[3] D. E. Kurniawan, S. Fani. 2017. Technomedia Journal (TMJ), Perancaangan Sistem Kamera Pengawas Berbasis Perangkat Bergerak Berbasis Raspberry Pi, 3(2): 140-146.

[4] I. Handayani. 2019. Technomedia Journal (TMJ), Optimalisasi Sistem dan Desain CCTV pada PT Jet Teknologi Express Berbasis Cloud, 4(2).

[5] Kristomson. H, Rosalia, H. Subrata, F. Gozali. 2018. Sistem Keamanan Ruangan Berbasis Internet of Things dengan Menggunakan Aplikasi Android. Jurnal Teknik Elektro, 20(2).

[6] D. A. Muktiawan, Nurfiana. 2016. Sistem Monitoring Penyimpanan Kebutuhan Pokok Berbasis Internet of Things (lot). Jurnal Sistem Informasi dan Telematika (Telekomunikasi, Multimedia, dan Informatika), 9(1).

[7] I. T. M. Daeng, N. N. Mewengkang, E. R. Kelesarang. 2017. Penggunaan Smartphone Dalam Menunjang Aktivitas Perkuliahan Oleh Mahasiswa Fispol Unsrat Manado. e-jurnal acta Diurna. 6(1): 1-15.

[8] A. Kusumawardhani, S. Nurdin, M. S. A. Ari. 2017. Teknologi Smartphone Android Dan Aplikasinya Sebagai Pengendali Pintu Air Daerah Aliran Sungai (DAS). Teknika: Engineering and Sains, 1(2): 89-94 